\title{
Changes on the Qualities of University Counsellors in China
}

\author{
Lan Wen \\ (Institute of Psychological and Education, South China Business College, \\ Guangdong University of Foreign Studies, windlives@163.com) \\ Peijue Zheng \\ (School of Interpreting and Translation Studies, Guangdong University of Foreign Studies, \\ 491367347@qq.com) \\ Shaogang Yang \\ (Institute of Psychological and Education, South China Business College, \\ Guangdong University of Foreign Studies, ysgrime@163.com)
}

\section{Literature Review}

Since 19th century, student affairs in American universities were separated from academic affairs to provide specific counselling for students' on issues such as psychological health, academic performance, and professional development, and thereby the job of "student affairs officer" emerged (Yanjun 2007). Although many scholars have concluded that student affairs officers play an important role on both formal and informal teaching occasions (Moore \& Marsh 2007). Gregory, a senior student affairs officer (SSAO) pointed out that, in fact, this job is not usually a career option for young people, and there aren't any relevant undergraduate courses available now to prepare students for this job (Blimling 2002). The earliest systematic study on student affairs in universities traces back to the theory proposed by Chickering in 1969. He put it forward that student affairs officers should be assessed based on 7 vectors related to students' development: Developing competence, Managing emotions, Developing autonomy, Establishing identity, Freeing interpersonal relationships, and Developing integrity (Moore \& Upcraft 1990). Mcclelland proposed 8 qualities for student affairs administrative staff, namely achievement orientation, analytical thinking, developing others, flexibility, impact and influence, information seeking, self-Confidence, and team leadership (McClelland 1998). Spreitzer McCall and Mahoney listed 14 dimensions of work potentials: Sensitive to Cultural Differences, Business Knowledge, Courage, Brings Out the Best in People, Integrity, Insightful, Committed, Takes Risks, Seeks Feedback, Uses Feedback, Is Culturally Adventurous, Seeks Learning Opportunities, Open to Criticism, and Flexibility (Spreitzer McCall \& Mahoney, 1997).

There are also specific studies on student affairs officers. Nicole believes student affairs experts must learn to be innovative, observant, make full use of resources at 
disposal and bear in mind the whole picture (Eramo 2006). Then Kidder shed light on the four criteria for student affairs staff recruitment: assessment, accountability, service learning, the value of cocurricular education efforts on campus (Kidder 2010). Buildng upon "Student Talent View" by American Council on Education (1937), Kathleen and Jeanne summarized 8 life aspects of students that student affairs officers are supposed to focus on: intellectual capacity and achievement, emotional make up, physical condition, social relationships, vocational aptitudes and skills, moral and religious values, economic resources , and aesthetic appreciations (Kerr \& Hart-Steffes 2012). American universities generally divide student counsellors into 5 categories based on their professional qualities: psychological counsellors, vocational counsellors, learning counsellors, life counsellors and accommodation counsellors (Ping 2006). Leilani Kupo concluded that for scholar-practitioners, multitasking has been a way of existence. It is a frame of mind. It includes navigating the realms of practitioner and scholar as well as having the ability to understand how to translate relevant research and data and incorporate it into daily practice (Leilani Kupo 2014).

It has been about 50 years since Chinese "University Counsellor System" was initiated by President Jiang Nanxiang of Tsinghua University in 1953, and the student affairs administrative staff were originally called "political counsellors". This system is intended to establish an ideological and political leading force among teachers and students to ensure the leadership of The Communist Party of China (CPC) over universities. The research on university counsellors began with research on their "qualities" or "competence". The early "ternary theory" divides counsellors' qualities into three categories: ideological and political qualities, literacy, professional competence (Wang Lifen 2001). At the same time, some scholars divide them into 4 aspects: political qualities, ideological and moral qualities, expertise and competency (Lin Sifeng 2004); or "leadership, coordination ability, literacy and the ability to summarize" (Sun Jiayan 2001). According to Zhang Shuming, counsellor qualities fall into 2 categories: basic qualities and basic abilities, respectively including political qualities, moral qualities, expertise, psychological qualities; and coordination ability, communication and cooperation ability, ability to serve students, ability to psychologically counsel students, scientific research and innovation ability, ability of self-control and addressing complex situations and linguistic proficiency (Zhang Shuming 2010). Gu Qian divides counsellor' professional qualities into 16 dimensions: expression ability, communication ability, adaptability, coordination ability, caring for students, innovation ability, observational acuteness, professionalism, ability to promote students' development, self-retrospection, personal charisma, moral standard, psychological counselling ability, the ability to understand and respect students, being principled, and the ability to engage in students' activities (Gu Qian 2004). Shao Guoping concluded 4 dimensions for occupational competence through modeling: education, management, service and professionalism (Shao Guoping 2013).

Furthermore, some scholars focus on the study of counsellors' competence. Yang 
has put forward the most important 5 qualities in terms of counsellors' competence as follows: understanding and respecting students, expression ability, being principled, caring for students, professionalism (Yang Jiping 2004). There is another 7-dimension model: professional competence, student-cultivating ability, moral qualities, professionalism, awareness for the whole picture, influence strategy, caring for students (Huo Xiaodan 2013). Moreover, there is also a two-level model with 8 factors at the first level and 12 factors at the second level. The 8 factors are social awareness, expertise, political and moral qualities, professionalism, personality, adaptability, professional skills, and values (Zou Tao 2017).

Since 2010, researches on qualities of university counsellors have begun to emerge. It is proposed that counsellors' professional qualities composition includes expertise, professional skills, professional ethics and professional affection (Ma Jing 2010). Zhang Jingpeng theorizes that qualities composition includes political qualities, ideological qualities, professional ethics, literacy, psychological qualities, competence (Zhang Jingpeng 2010). Based on the above review, it is realized that most previous studies only theoretically analyzed the qualities composition of counsellors with highly subjective research methods. There are few empirical studies employing research methods such as survey and mathematical analysis, therefore lacking reliability, validity, and item analysis.

\section{Methods and Findings}

Chinese university faculty members and students are our subjects. The pre-test is based on Likert 7 point scale ( 1 = disagree very much, 7 = agree very much). SPSS22.0 and AMOS21.0 are applied to data analysis and processing. The correlation coefficient between each question in the questionnaire and the total score will be calculated after the test, and all the questions with correlation coefficient $r<0.4$ will be eliminated until only 51 questions are left. Exploratory Factor Analysis (EFA) shows that 9 factors were extracted, the cumulative variance contribution rate reaches $82.83 \%$ and the model tends to be stable. Then the final version of questionnaire titled „university counsellors' qualities questionnaire" is completed with 54 items in total, among which 3 are lie detection questions. Of 800 pieces circulated, 696 pieces are collected, and 537 pieces are found to be effective after the screening through lie detection questions .

The results show that Cronbach's alpha coefficient and the split-half reliability coefficient are all above 0.9 , indicating that the actual value is in good accordance with the true value. The internal alpha coefficient and the split-half reliability coefficient of the 5 factors are all above 0.8. Correlation analysis between the 5 sub-scales and the total scale of the test shows that the correlation coefficients are all above 0.8. The correlation coefficients between different sub-scales range from 0.7 to 0.9 , indicating that there's relatively high correlation between these sub-scales, various factors are closely connected, and that the structure validity of the test is high. 


\begin{tabular}{|l|c|c|c|}
\hline Factor & Number of item & $\begin{array}{c}\text { Cronbach's } \alpha \\
\text { coefficient }\end{array}$ & $\begin{array}{c}\text { Split-half } \\
\text { reliability }\end{array}$ \\
\hline Moral quality & 15 & 0.95 & 0.93 \\
\hline Business execution & 14 & 0.96 & 0.95 \\
\hline Political consciousness & 10 & 0.93 & 0.90 \\
\hline Guiding strategy & 7 & 0.87 & 0.85 \\
\hline $\begin{array}{l}\text { Interpersonal } \\
\text { coordination }\end{array}$ & 5 & 0.85 & 0.86 \\
\hline Total test & 51 & 0.98 & 0.95 \\
\hline
\end{tabular}

Table 1: Test reliability

A 5-factor model is formulated based on the research results, including: moral quality; professional competence; political awareness; instructive ability; interpersonal skills. KMO is 0.979 , which is a very suitable figure for factor analysis. Bartlett's test of sphericity is $23516.560, \mathrm{df}=1275, \mathrm{P}<0.001$, the cumulative variance has reached $65.72 \%$, all 51 items are included in the EFA model.

We have conducted confirmatory factor analysis has been performed on the data, showing all fit indexes of this model are sound. $X^{2} / d f<5$, indicating that the model is acceptable. The closer GFI, AGFI, NFI, CFI, and IFI are to 1, the higher the fitness is, and it is more desirable if RMSEA is close to 0 .

\begin{tabular}{|l|l|l|l|l|l|l|l|l|l|}
\hline & $\mathrm{X}^{2}$ & $\mathrm{f}$ & $\mathrm{X}^{2} / \mathrm{df}$ & GFI & AGFI & NFI & CFI & IFI & RMSEA \\
\hline Model Fit & 4411.32 & 214 & 3.634 & 0.74 & 0.71 & 0.82 & 0.86 & 0.86 & 0.07 \\
\hline
\end{tabular}

Table 2: Model Fit.

Moral quality refers to that counsellors' daily behaviors should follow wellaccepted moral standards, being a role model for students so as to help them develop correct values, outlooks on life and the world as a whole. Professional competence is indispensable skills that counsellors have to acquire to handle daily work involving many aspects such as leadership, instruction, observation, management, coordination, communication and practice. Political awareness puts much weight on political and legal knowledge. Counsellors are supposed to be familiar with Party-related paperwork, school regulations to ensure daily work is done in compliance with laws and regulations. Instructive ability mainly has to do with counsellors' ability to guide students' longterm development and to foster the leadership of students. As we step into new eras, the counsellors are expected to master more extracurricular, social and internet studentinstructing strategies so that education can keep pace with the times. Interpersonal skills involve the skills of communication and emotional interaction with students. Even if the 
counsellors are under immense work pressure, they should be able to adjust themselves and still be generous and forgiving with students.

This 5-factor model reflects the evaluation of faculty members and students in universities on qualities of counsellors and transformation in their expectation for the role counsellors play as time goes by. On the one hand, counsellors are expected to be competent in problem-solving and management; on the other hand, they are also required to serve as an exemplar with their own uprightness and honorable deeds to help students form positive as well as correct outlooks on value, life and the world. In addition, counsellors ought to have a high political awareness, which is characterized by being well-informed of Party paperwork, laws and regulations to ensure work is carried out in their compliance. Counsellors' work runs a whole gamut of management from Party paperwork, student associations, scholarship, student loans and subsidies, suspension or dropping out of school, student registration affairs, graduation and employment, student behaviour monitoring, dormitory management and so on.

\section{The Changes}

The qualities of counsellors are constantly changing without deviating from intrinsic nature of student affairs. These changes are based on the realistic situations and the current and future developmental needs of student administration.

\subsection{Objectivity of times}

The qualities of counsellor is characterized by objectivity, and its existence, development and changes are affected by the objective environment. The new situations and demands arising from social progress drive the reform in student administration models and ideas, and in professional qualities composition of counsellors so that they are in line with the ever-changing educational environment. The comprehensive application of new technologies have rapid and irresistible impact on the counsellors' professional qualities and working environment. It even can cause qualitative changes in their mindset. In this case, qualities such as communication skills and abilities to operate new media are included in our questionnaire. A great deal proportion of student affairs have been handled online so that they can be carried out in a low-cost, low-entry-threshold, high-efficiency manner. This is a testimony to the phenomenal development of student administration in this new era.

\subsection{Initiative of inner}

Despite the objectivity of counsellors' professional qualities, they are also in a way influenced by counsellors' subjectivity, which are internal factors leading to the changes in their qualities. The subjectivity is manifested in counsellors' awareness for their own professional qualities, namely their own ability to evaluate and reflect on their qualities, in the- 
ir ability to perceive and respond to changes in physical working environment, namely the ability to judge the compatibility between their own professional qualities and the working environment, the ability to look into the future, to grasp the rules of student administration in the future, the ability to explore and forge an optimal professional qualities composition. Self-awareness, perception and response ability and the ability to live by the natural rules of student administration constitute the subjectivity of counsellors themselves.

\subsection{Predictability of practice}

The changes in counsellor's professional qualities are positive ones in accordance with the reality and objective rules, which therefore can be recognized, predicted and even created. Only by conducting abundant investigation, keeping updated on the situation, acquiring field experience and carrying out lone-term observation, analysis, camparison can the counsellors form systematic and correct understanding, predict the developmental trend of student administration, make foresighted decisions to guide counsellors' future professional practices and improve the feasibility, scientificity and practicality of their practices. In other words, the predictability of the future comes from the reliable understanding of the reality, the profound mastery of the natural rules of development, and the logical analysis for the future trend.

In China, people lay emphasis on counsellors' ideological and political qualities, instructing skills, and transferable skills to organize, serve students and promote their long-term development and psychological health. The professionalization of the counsellors fundamentally requires this career to be sustainable, stable and widelyreceived by the society (Zhu Ping 2007). Being well aware of the trend of this career is conducive to the formation of a sound relationship between counsellors and students, measurability for morality-oriented education, and improvement in counsellors' overall qualities.

\section{References}

Blimling G. S. 2002. "Reflections on Career Development Among Student Affairs Leaders." New Directions for Student Services 98:27-36.

Eramo N. P. 2006. „Rethinking Student Affairs Practice.” Journal of Colleges Student Development 123-5.

Gu Qian. 2004. Compilation and Preliminary Application of College Counsellors' Competency Questionnaire. Shanxi: Shanxi University Editions.

Huo Xiaodan. 2013. Quality Standards and Development of College Counsellors - Analysis Based on Competency Model. Beijing: Peking University Press. 
Kerr G. \& Hart-Steffes J. S. 2012. „Sustainability, Student Affairs, and Students.” New Directions for Student Services 137:7-17.

Kidder R. 2010. „Administrators Engaging in the Research Process.” ACPA Developments $8(1)$.

Lan Haitao \& Wei Xing. 2017. „The Quality and Ability Structure of College Counsellors and Their Training Methods." China Higher Education 5:42-44.

Leilani Kupo V. 2014. „Becoming a Scholar-Practitioner in Student Affairs.” New Directions for Student Services 147.

Lin Sifeng. 2004. „Reflections on Strengthening Quality Training of Political Counsellor Team." Journal of Jimei University (Philosophy and Social Sciences) 2.

McClelland D. C. 1998. „Identifying Competencies with Behavioral-event Interviews.” Psychology Science 9(5):331-9.

Moore E. L. \& Marsh R. S. 2007. "College Teaching for Student Affairs Professionals.” New Directions for Student Services 117:3-11.

Moore L. V. M. \& Upcraft L. 1990. „Theory in Student Affairs: Evolving Perspectives.” New Directions for Student Services 51:3-23.

Shao Guoping, Miao Delu, \& Yang Lin. 2013. „The Structure and Measurement of Occupational Ability in College Counsellors." Psychological Research 6(2):85-89.

Spreitzer G. M., McCall M. W. Jr., \& Mahoney J. D. 1997. „Early Identification of International Executive Potential." Journal of Applied Psychology 82(1):6-29.

Sun Jiayan. 2001. „Discussion on the Qualities That College Counsellors Should Have.” Journal of Social Science of Jiamusi University 4.

Wang Lifen. 2001. „On the Quality of University Instructors.” Journal of Taiyuan University of Technology (Social Sciences Edition) 3:114-6.

Yan Ping. 2006. „Comparison of The Work of College Instructors in China and The United States - A Brief Discussion on the Development Direction of China's College Counsellor System." Journal of Huna Mass Media Vocational Technical College 7:115-6.

Yang Jiping \& Gu Qian. 2014. „A Preliminary Study on the Competency of College Counsellors." Journal of Shanxi University (Philosophy and Social Sciences) 12.

Zhang Jingpeng. 2010. Research on Role Orientation and Professional Quality of College Counsellors. Shenyang: Shenyang Aerospace University.

Zhang Shuming. 2010. College Counsellors' Team Building. Jinan: Mountain Tai Press. Zhang Yanjun. 2007. „Comparing the Recruitment Conditions of College Counsellors between China and the United States." Journal of Nantong University (Education and Science) 23(3):40-43.

Zhu Ping. 2007. „Interpretation of College Instructor’ s Professionalization and Specialization." Journal of Anhui Normal University (Humanities and Social Sciences) 35(2):218-223. 
Zou Tao, Ai Hong, \& Chen Xiang. 2017. „A Study on The Difference Assessment of Instructor Competency Based on The Empirical Survey of Three Groups of College Students." Journal of Southwest University of Nationalities (Humanities and Social Sciences) 1:222-227.

\section{Acknowledgements}

The study was conducted as a part of moral education project (code number: 2017JKDY16), 2017; Guangdong high education Grant of Special Creativity (Humanities and social science); Young Creative talents project (code number: 2017WQNCX208), 2016; and Guangdong Philosophy and social science "13th fiveyear plan" project (code number: GD16XJY31). 


\title{
Lan Wen, Peijue Zheng, Shaogang Yang
}

(Guangdong)

\section{Changes on the Qualities of University Counsellors in China}

\begin{abstract}
Counsellors are important key members in Chinese universities. In this paper, on the one hand, we compared student affairs workers' occupational characteristics, classification and development of western as well as Chinese university. On the other hand, Chinese university faculty members and students are our subjects. Of 800 pieces circulated, 537 pieces are found to be effective. We verified the reliability and validity of data, then conducted correlation analysis, exploratory factor analysis (EFA), and confirmatory factor analysis (CFA). The test has good reliability and validity. Cronbach's alpha coefficient and the split-half reliability coefficient are all above 0.9 , indicating that the actual value is in good accordance with the true value. The internal alpha coefficient and the split-half reliability coefficient of each factor are all above $0.8 . X^{2} / d f<5$. GFI, AGFI, NFI, CFI, IFI, RMSEA and the other indicators are fitting, and this test meets measurement requirements. A 5-factor model is formulated based on the research results, including: moral quality; professional competence; political awareness; instructive ability; interpersonal skills. This 5 -factor model reflects the evaluation of faculty members and students in universities on qualities of counsellors and transformation in their expectation for the role counsellors play as time goes by. So we summarize the qualities of counsellors are constantly changing. These changes have been constantly evolving in time, and their traits are such as: Objectivity of the times, Initiative of inner, Predictability of practice. Being well aware of the trend of this career is conducive to the formation of a sound relationship between counsellors and students, measurability for morality-oriented education, and improvement in counsellors' overall qualities.
\end{abstract}

Keywords: University counsellor; quality; changes; China.

Ethics in Progress (ISSN 2084-9257). Vol. 9 (2018). No. 1, Art. \#9, pp. 174-182.

Creative Commons BY-SA 3.0

Doi: 10.14746/eip.2018.1.9 